\title{
Competitive advantage effects on firm performance: A Case study of startups in Thailand
}

\author{
Pisit Potjanajaruwit \\ Faculty of Management Science, Suan Sunandha Rajabhat University \\ Thailand \\ Pisit.po@ssru.ac.th
}

Abstract. This research had the primary objective to study the causal factors of technological capability and interorganizational collaboration that affect competitive advantage of startups in Thailand. This research was a mixed methods research that encompassed both qualitative and quantitative tools through the use of in-depth interviews and questionnaires. The sample employed in this research consisted of entrepreneurs and executives of startups in Thailand that were selected using a stratified random sampling method. A path analysis was used to analyse the obtained data in order to validate the research findings. From the obtained results, it became evident that the causal

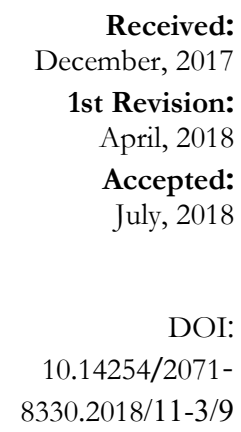

Received:

December, 2017

1st Revision:

April, 2018

Accepted:

July, 2018

DOI: factors of technological capability and interorganizational collaboration had a direct positive effect on the competitive advantage of startups, and competitive advantage had a direct positive effect on the performance of startups in Thailand. Furthermore, it was apparent that technological capability and interorganizational collaboration had a direct effect on the performance of startups in Thailand, whereby all of the foregoing effects were statistically significant.

Keywords: Competitive advantage, technological capability, interorganizational collaboration, startup performance

\section{JEL Classification: N514.}

\section{INTRODUCTION}

In the era of rapid changes in business competition, the capability in the development of startups, including both product and process innovations, has become the key driver of growth and technological advance of businesses. Nonetheless, in the context of startups, innovation embraces high complexity due to the presence of technological advancement that leads to rapid continual development of innovation to fulfill the changing needs and preferences of consumers. With that respect, startups must seek for 
strategies and ways to create new innovations in order to gain new competitive advantage. Despite the obviousness of this trend, the majority of entrepreneurs do not place importance on innovation and many businesses lack knowledge for transforming into innovative enterprises. Some other businesses solely emphasize on technological innovations, while neglecting other types of innovations, such as economic innovation that encompasses an incorporation of new concepts, new ways of utilizing the available resources to create economic benefits, or application of differentiation on the basis of transforming changes into opportunities to getboth personal and social benefits. Indeed, this conforms to the research of (Makanyeza and Dzvuke, 2015), who examined the effects of innovations on the performance of small and medium-sized enterprises (SMEs) in Zimbabwe. The results of their research indicated that the capability of SMEs in the aspects of innovation, learning, and communication had an overall positive effect on their performance in terms of customer relations, internal processes, and finance with statistical significance. These results are in line with the research of (Zhang and Hartley, 2018), who studied the effects of information system and innovation on firm performance. Their research found that innovation played an important role in building competitive advantage and reducing the costs of business operations. Nevertheless, it is undoubtedly challenging for an organization to succeed from being a sole innovator; it is essential for an organization to establish a network of business alliances to strengthen collaboration in the supply chain, such as exchanging information, knowledge, and operational techniques.

Accordingly, interorganizational collaboration plays a crucial role in the development and adoption of technologies. Organizations must collaborate with external agencies, including research promotion agencies, suppliers, and consumers, to be integrated into a network of innovation for exchange of knowledge and for sharing the benefits from the development of products and operational processes. Unfortunately, there are problems concerning the interorganizational collaboration of startups. Specifically, there is a lack of collaboration between public and private sectors in the aspects of sales and marketing, as well as an inadequacy of research and development through cooperation of business alliances while developing products and services. This conforms to the research of (Zeng, Xin, and Tam, 2010), that examined the relationship between interorganizational collaboration and innovation efficiency of startups. Their results illustrated that interorganizational collaboration had a positive effect on the innovation efficiency of startups. Moreover, it was evident that interorganizational collaboration contributed to the improved performance of startups, and can be used to develop competitive advantage in a sustainable manner, while eliminating the limitations of operational resources. These findings are consistent with the research of (Alessandro, 2014), who studied the effects of interorganizational collaboration on the production capacity of startups in Italy. Their research had the objectives to examine the effects of interorganizational collaboration, which comprises the aspects of sales, marketing, and knowledge dissemination, on the production capacity and competitive advantages of startups in terms of cost leadership. According to the survey of 276 startups, the results indicated that interorganizational collaboration in the aspect of technological knowledge dissemination led to a cost competitive advantage by reducing both manufacturing and operating costs. With that respect, businesses in Thailand are inevitably encountered with significant changes, both domestically and internationally, that have become increasingly more intricate, particularly in the spheres of technological and innovation capabilities and interorganizational collaboration that affect competitive advantage and firm performance. Indeed, this business condition conforms to the research findings of (Paolo \& Elisabetta, 2015) and (Daud, Ahmad, \& Azwardi, 2014), both studying the relationship between technological and innovation capabilities, interorganizational collaboration, and competitive advantage that have influence on firm performance.

With regards to the aforementioned reasons, the researcher was intrigued to study the effects of competitive advantage on the performance of startups in Thailand with the ultimate goals to: 1) determine the influence of causal factors of technological capability and interorganizational collaboration towards the 
competitive advantage of startups; and 2) study the effects of competitive advantage on the performance of startups in Thailand. The hypotheses of this research have been formulated as follows.

Hypothesis 1: Technological capability has a direct effect on the competitive advantage of startups in Thailand.

Hypothesis 2: Interorganizational collaboration has a direct effect on the competitive advantage of startups in Thailand.

Hypothesis 3: Competitive advantage has a direct effect on the performance of startups in Thailand.

\section{LITERATURE REVIEW}

\subsection{Competitive advantage}

The concept of competitive advantage in small and medium-sized enterprises was invented by (Sultan, S., \& Mason, M., 2010) who explained that the sustainability of a business is achieved through competitive advantage; whereby upon the formulation of business strategies, it is necessary to create values to customers. Such values may be in the aspect of cost leadership that presents products and services to customers at appropriate prices, the aspect of differentiation of products and services, or the aspect of better responsiveness to customer needs in the niche market than competitors in the same industry. Indeed, competitive advantage is regarded as the ability of the organization to differentiate itself from other competitors. Furthermore, competitive advantage is also an essential foundation for devising business strategies to attain sustainable growth (Simpson, M., Taylor, N., \& Barker, K., 2004). The important elements of competitive advantage pertaining to the creation of values to customers were developed by (Jones, O., 2003). He invented three generic strategies, which comprise of cost leadership, differentiation, and focus. Such competitive strategies are able to respond to the objectives of businesses effectively and are commonly adopted by businesses. As such, in order for businesses to achieve competitive advantage, it is necessary to create economic values to customers (Barney and Hesterly, 2010). Hence, the creation of competitive advantage that encompasses all of the business processes should primarily take into consideration the values presented to customers. Once the customers have acknowledged the values of products and services, they will be able to differentiate such products and services from those of the competitors. Nonetheless, in the case of startup businesses that are faced with aggressive competition, the creation of competitive advantage depends on the environment of the business. In general, competitive advantage can be categorized into three types: 1) cost leadership in presenting products and services at the lowest price in the industry; 2) differentiation of products and services; and 3) responsiveness to the needs of a specifically targeted segment. Meanwhile, the strategic options of the competitive advantage for SMEs and startups are considerably flexible, concerning the fact that they depend on market demand, business environment, and internal and external factors that facilitate the establishment of competitive advantage (Gassmann, O., \& Keupp, M. M., 2007). With that regards, startup entrepreneurs have to dedicate their energy, resources, business capability, and collaborative network of suppliers and intermediaries in order to create the competitive advantage in all activities of the value chain (Pavic, S. C. L. K., Koh, S. C. L., Simpson, M., \& Padmore, J., 2007).Such factors will lead to the success of the organization in establishing a competitive advantage, which can be further utilized in devising a business strategy to achieve sustainable growth and survivability. Since the creation of competitive advantage varies with the business environment, whether in the aspects of the use of technology or interorganizational collaboration, the ability of each organization in establishing a competitive advantage will differ. Such statement is indeed consistent with Zaridis (2009) who asserted 
that competitive advantage is a significant matter for startups, since it leads to sustainability and survivability of the business as a result of an effective management of internal and external resources. Accordingly, businesses should analyse both internal and external factors pertaining to the business environment. Likewise, it is necessary to construct the competitive advantage in the aspects of cost leadership, differentiation of products and services, and responsiveness to the needs of a specific group of customers to be in accordance with the opportunities and obstacles of both internal and external environments of the organization. Such practice indeed conforms to the theory on the optimal utilization of resources to create product differentiation. Moreover, it also enables the business to distinctively differentiate itself from competitors in the same industry and effectively prevent the obstacles of substitute products.

\section{METHODOLOGY}

This research on the effects of competitive advantage on the performance of startups in Thailand was a mixed methods research, which is a combination of qualitative and quantitative research (Creswell, 2009). The research was conducted in two parts. The first part was a qualitative research in which data were collected from the in-depth interviews with startup entrepreneurs in Thailand. Meanwhile, the second part was a quantitative research wherein data were collected from questionnaires, which were administered to the executives and entrepreneurs of startups in Thailand. The sample were selected using a probability sampling method (Nachmias, 1993) and a stratified random sampling method, and were divided into eight sub-groups, comprising 420 respondents (Office of Small and Medium Enterprises Promotion, 2017).

Table 1

The ratio of the entrepreneurs categorize by performance of startup businesses in Thailand

\begin{tabular}{|l|c|c|c|}
\hline \multicolumn{1}{|c|}{$\begin{array}{c}\text { Performance of Startup Businesses in Thailand )With } \\
\text { Disclosure of Information( 8 Regions }\end{array}$} & $\begin{array}{c}\text { Number of } \\
\text { Entrepreneurs }\end{array}$ & $\begin{array}{c}\text { Number of } \\
\text { Sample }\end{array}$ & Percentage \\
\hline (1) Entrepreneurs in Bangkok Region & 934 & 284 & 67.62 \\
\hline (2) Entrepreneurs in Metropolitan Region & 262 & 80 & 19.05 \\
\hline (3) Entrepreneurs in Central Region & 31 & 9 & 0.48 \\
\hline (4) Entrepreneurs in Western Region & 41 & 12 & 2.86 \\
\hline (5) Entrepreneurs in Eastern Region & 23 & 7 & 1.67 \\
\hline (6) Entrepreneurs in Northeastern Region & 44 & 13 & 3.09 \\
\hline (7) Entrepreneurs in Northern Region & 42 & 13 & 3.09 \\
\hline (8) Entrepreneurs in Southern Region & 1,384 & 420 & 100 \\
\hline Total & & & 2 \\
\hline
\end{tabular}

Source: (Office of Small and Medium Enterprises Promotion, 2017)

A survey research was then conducted by employing the questionnaires of Fowler (2013). This conforms to the research of Sibel (2015), which examined factors that affect the efficiency of the competitive advantage of SMEs in Bulgaria by studying entrepreneurs and executives of SMEs on the 
basis of their technological and innovation capabilities and interorganizational collaboration in creating competitive advantage. The research findings indicated that technological and innovation capabilities led to changes in the operational process, which subsequently resulted in a cost competitive advantage. Furthermore, it was evident that interorganizational collaboration contributed to an increased efficiency in the production and operational processes.

\section{EMPIRICAL RESULTS AND DISCUSSION}

Upon the analysis of factors that directly affected the variables of the competitive advantage of startups (CAS), it was evident that such variables were directly influenced by technological capability and interorganizational collaboration, with the sizes of direct effects equaled to 0.53 and 0.20 respectively, at a significance level of 0.01 . In addition to the direct and indirect effects that impacted the competitive advantage of startups (CAS), there was another variable that also received the direct effects. Such variable was the startup firm performance (SFP), which was directly affected by technological capability (TC) and competitive advantage of startups (CAS), with the effect sizes of -0.98 and 1.90 , respectively, at a significance level of 0.01 . Moreover, the performance of startups was also directly influenced by interorganizational collaboration (IC) at the effect size of 0.09 , with no statistical significance. In addition, such variable was indirectly affected by technological capability (TC) and interorganizational collaboration (IC) with the effect sizes of 0.37 and 0.39 , respectively, at a significance level of 0.01 .

Table 2

Analysis of the effects of variables in the causal model of factors that affected the competitive advantage and performance of startups in the sample

\begin{tabular}{|c|c|c|c|c|c|c|c|c|c|}
\hline Causes & \multicolumn{3}{|c|}{ TC } & \multicolumn{3}{c|}{ IC } & \multicolumn{3}{c|}{ CAS } \\
\hline Effects & TE & IE & DE & TE & IE & DE & TE & IE & DE \\
\hline CAS & $0.53^{* *}$ & - & $0.53^{* *}$ & $0.20^{* *}$ & - & $0.20^{* *}$ & - & - & - \\
\hline & ) 0.04( & - & ) 0.04( & ) 0.03( & - & ) 0.03( & - & - & - \\
\hline SFP & 0.03 & $1.00^{* *}$ & $-0.98^{* *}$ & $0.37^{* *}$ & $0.37^{* *}$ & - & $1.90^{* *}$ & - & $1.90^{* *}$ \\
\hline & ) 0.03( & ) 0.08( & ) 0.08( & ) 0.05( & ) 0.05( & - & ) 0.08( & - & 0.08( \\
\hline Statistics & & & & & & & & \\
\hline Chi-Square $=0.15, \mathrm{df}=1, \mathrm{P}=0.69796$, GFI $=1.00$, AGFI $=1.00, \mathrm{RMR}=0.00$, RMSEA $=0.00$ & \\
\hline Structural Equation of Variables \\
\hline
\end{tabular}

Source: Authors 'results. ${ }^{* * *}$ indicates significance level at 0.01 level.

According to the results, the correlation matrix of latent variables had values in the range of $0.62-$ 0.80. All pairs of variables were positively correlated, with two pairs of latent variables that were very highly correlated $(r>0.8)$. The highest correlation efficient was 0.80 . The pairs of latent variables that were very highly correlated consisted of interorganizational collaboration (IC) and startup firm 
performance (SFP) with the correlation efficient ( $r$ ) of 0.80 , and technological capability (TC) and competitive advantage of startups (CAS) with the correlation efficient (r) of 0.81 .

Table 3

The Analysis of the Correlation Matrix of Latent Variables

\begin{tabular}{|c|c|c|c|c|}
\hline \multicolumn{5}{|c|}{ Correlation Matrix of Latent Variables } \\
\hline Latent Variables & CAS & SFP & TC & IC \\
\hline CAS & 1.00 & & & \\
\hline SFP & 0.66 & 1.00 & & 1.00 \\
\hline TC & 0.81 & 0.62 & 0.70 & 1.00 \\
\hline IC & 0.74 & 0.80 & & \\
\hline
\end{tabular}

Source: Authors' results. *** indicates significance level at 0.01 level.

Alternatively, there were three pairs of latent variables that were highly correlated $(0.6<\mathrm{r}<0.8)$, comprising of: interorganizational collaboration (IC) and competitive advantage of startups (CAS) with the correlation efficient (r) of 0.74 ; technological capability (TC) and interorganizational collaboration (IC) with the correlation efficient (r) of 0.70; and technological capability (TC) and startup firm performance (SFP) with the correlation efficient (r) of 0.66 .

\section{CONCLUSION}

Upon consideration of the goodness of fit index (GFI), it was evident that the hypothesized model fitted with the empirical data. All six indices passed the criterion of acceptance: $\chi 2 / \mathrm{df}=1.06, \mathrm{CFI}=1.00$, GFI $=0.97$, AGFI $=0.95$, RMSEA $=0.01$, and SRMR $=0.02$. Accordingly, it was concluded that the structural equation modeling was appropriate and fitted with the empirical data, which could be explained as follows: (1) the normalized chi-square $\left(\chi^{2 / \mathrm{df}}\right)$ was equal to 1.06 , which indicated that the model fitted with the empirical data since the value was lower than 2.00; (2) the comparative fit index (CFI) was equal to 1.00, which indicated that the model fitted with the empirical data since the value was greater than 0.90 ; (3) the absolute fit index was measured based on two indices that consisted of goodness of fit index (GFI) with the value of 0.70 and adjusted goodness of fit index (AGFI) with the value of 0.95 , which indicated that the model fitted with the empirical data since the two values were between 0 and 1 , and the accepted values of GFI and AGFI were greater than 0.90; (4) the root mean square error of approximation (RMSEA) was equal to 0.01, which indicated that the model somewhat fitted with the empirical data since the value was lower than 0.05 or between 0.05 and 0.08 ; and (5) the standardized root mean square residual (SRMR) was equal to 0.02 , which indicate that the model fitted with the empirical data since the value was lower than 0.05 . These results were in accordance with the research of (Suzanne Rivarda*, Louis Raymondb, David Verreaultc, 2006), which examined the applications of technological innovation in the establishment of competitive advantage that affected the performance of startups in Canada. Their research had the objectives to study and understand the creation of competitive advantage through the differentiation of technological capability and its effects on the performance of businesses in the aspects of finance and customer satisfaction. According to their findings, the use of technology in communication and learning was able to differentiate the products and services, which directly affected the performance of startup businesses in the aspect of finance and customer satisfaction with statistical significance. Such 
findings also conformed to the researches of (Sefer Şenera*, Mesut Savrulb, Orhan Aydına, 2014) which found that the competitive advantage in the aspects of differentiation and cost reduction, through the applications of technological innovation, directly affected the performance of startup businesses with statistical significance. In other words, information technology is able to reduce costs and differentiate products and services of the business to obtain the competitive advantage over competitors in the same industry that use low level of technology. In addition, information technology was also found to reduce the operating costs, which subsequently contributes to a significant growth in the financial performance of the business. Such finding was consistent with the research of (Melville et al., 2004), which asserted that the efficiency of the performance of startup businesses was primarily measured from the addition of value as a result of the reduction of operating costs. (Similarly, Bharadwaj, 2000) and (Santhanam and Hartono, 2003) explained that the performance of businesses was mostly measured from the financial ratio.

\section{ACKNOWLEDGEMENT}

The author would like to thank Assoc. Prof. Dr. Luedech Girdwichai, The President of Suan Sunandha Rajabhat University, Bangkok, Thailand for financial support. In addition, the author would like to thank to Asst. Prof. Dr. Prateep Wajeetongratana, the Dean of Faculty of Management Science for the full support in this research.

\section{REFERENCES}

Barney, J. B., \& Hesterly, W. S. (2010). VRIO framework. Strategic management and competitive advantage, 68-86.

Bharadwaj, A. S. (2000). A resource-based perspective on information technology capability and firm performance: an empirical investigation. MIS quarterly, 169-196.

Creswell, J., (2009). Research design: Qualitative, quantitative, and mixed methods approaches. SAGE Publications, Incorporated.

Fowler Jr, F. J. (2013). Survey research methods. Sage publications.

Gassmann, O., \& Keupp, M. M. (2007). The competitive advantage of early and rapidly internationalising SMEs in the biotechnology industry: A knowledge-based view. Journal of World Business, 42(3), 350-366

Jones, O. (2003). Competitive advantage in SMEs: towards a conceptual framework. Competitive advantage in SMEs: Organising for innovation and change, 15-33..

Makanyeza, C., \& Dzvuke, G. (2015). The influence of innovation on the performance of small and medium enterprises in Zimbabwe. Journal of African Business, 16(1-2), 198-214.

Md Daud Ismaila, Ahmad Khairy Ahmad Domila, Azwardi Md Isa (2014). Managerial competence, relationship quality and competitive advantage among SME exporters. Procedia-Social and Behavioral Sciences, 115, 138-146.

Melville, N., Kraemer, K., \& Gurbaxani, V. (2004). Information technology and organizational performance: An integrative model of IT business value. MIS quarterly, 28(2), 283-322.

Muscio, A. (2007). The impact of absorptive capacity on SMEs' collaboration. Economics of Innovation and New Technology, 16(8), 653-668. DOI: 10.1080/10438590600983994

Nachmias. (1993). Research methods in the social sciences (7th ed.). New York: Worth Publishers.

Neirotti, P., Raguseo, E., \& Paolucci, E. (2018). How SMEs develop ICT-based capabilities in response to their environment: Past evidence and implications for the uptake of the new ICT paradigm. Journal of Enterprise Information Management, 31(1), 10-37.

Pavic, S. C. L. K., Koh, S. C. L., Simpson, M., \& Padmore, J. (2007). Could e-business create a competitive advantage in UK SMEs?. Benchmarking: An International Journal, 14(3), 320-351..

Rivard, S., Raymond, L., \& Verreault, D. (2006). Resource-based view and competitive strategy: An integrated model of the contribution of information technology to firm performance. The Journal of Strategic Information Systems, 15(1), 29-50.

Santhanam, R., \& Hartono, E. (2003). Issues in linking information technology capability to firm performance. MIS quarterly, 125-153. 
Şener, S., Savrul, M., \& Aydın, O. (2014). Structure of small and medium-sized enterprises in Turkey and global competitiveness strategies. Procedia-Social and Behavioral Sciences, 150, 212-221.

Sibel Ahmedova. (2015) Factors for increasing the competitiveness of small and medium-sized enterprises (SMEs) in Bulgaria. Procedia-Social and Behavioral Sciences, 195, 1104-1112.

Simpson, M., Taylor, N., \& Barker, K. (2004). Environmental responsibility in SMEs: does it deliver competitive advantage?. Business strategy and the environment, 13(3), 156-171.

Sultan, S., \& Mason, M. (2010). Competitive Advantage of SMEs.

Syed Zamberi Ahmada, Norita Ahmadb, Abdul Rahim Abu Bakarc. (2017). Reflections of entrepreneurs of small and medium-sized enterprises concerning the adoption of social media and its impact on performance outcomes: Evidence from the UAE. Telematics and Informatics.

Zaridis, A. D. (2009, August). Competitive advantage and its sources in an evolving market. In AIP Conference Proceedings (Vol. 1148, No. 1, pp. 917-921). AIP.

Zeng, S. X., Xie, X. M., \& Tam, C. M. (2010). Relationship between cooperation networks and innovation performance of SMEs. Technovation, 30(3), 181-194.

Zhang, M., \& Hartley, J. L. (2018). Guanxi, IT systems, and innovation capability: The moderating role of proactiveness. Journal of Business Research, 90, 75-86. 